\title{
MAKING THE FIRST GLOBAL SOCIETY FOR HEALTH SYSTEMS RESEARCH TRULY GLOBAL
}

\section{Commentary on the Second Global Symposium on Health Systems Research in Beijing, 31 October-3 November 2012}

\author{
Jeffrey V. Lazarus ${ }^{1}$, Dina Balabanova², Martin $\mathrm{McKee}^{2}$ \\ ${ }^{1} \mathrm{CHIP}$, Copenhagen University, Copenhagen, Denmark \\ ${ }^{2}$ London School of Hygiene and Tropical Medicine, London, United Kingdom
}

\begin{abstract}
On 3 November 2012, Health Systems Global was launched at the Second Global Symposium on Health Systems Research, in Beijing. Health Systems Global is an international membership organisation entirely dedicated to promoting cross-disciplinary health systems research and knowledge translation. Its launch was attended by almost 2,000 people from across the globe. Yet, one geographical region was almost entirely unrepresented: the countries of Central and Eastern Europe and the former Soviet Union (CEE/FSU). In this commentary we ask why this region has such a small presence in health systems research.
\end{abstract}

Health Systems Global grew out of the Montreux First Global Symposium on Health Systems Research in 2010, held under the auspices of the World Health Organization. The more than 1,200 participants in Montreux realized that they had found a home: a conference designed by and for health systems experts. Yet, what would the future hold? A meeting at the end of the event led to the decision to create a new society, and Health Systems Global was formally launched two years later in Beijing (1). Health Systems Global seeks to serve all researchers, implementers and decision-makers who have an interest in the creation and practical application of new knowledge about health systems. However, only a handful of those present at the Beijing symposium were from CEE/FSU. The symposium's presentations were dominated by research on sub-Saharan Africa, Asia and Latin America, maintaining a pattern seen in previous global conferences on health systems research. This pattern is consistent with a recent bibliometric analysis of capacity for health research (2).

The absence of researchers from CEE/FSU is unfortunate. Many of the problems that these countries confront are the same as those in other middle-income countries, such as retention of health workers, equitable access to care, governance and the implementation of evidence-based care. Furthermore, middleincome countries worldwide face the common challenges of ageing populations and a rising tide of non-communicable diseases, both of which demand much more complex strategies than those employed in response to infectious diseases that dominated the disease burden in the past. Health Systems Global offers a forum for sharing knowledge about such issues globally.

In our experience, there is a huge thirst for information about the health systems of European countries that have been undergoing major political, social and economic transitions over the past two decades. In particular, there is interest in how middle-income countries such as Estonia and Slovenia have achieved and retained universal health coverage at a time when countries elsewhere are struggling with this challenge. Moreover, many low-income countries look at the countries of the former Soviet Union as examples of the successful scale-up of basic health interventions in the 1950s and 1960s. Health system responses to the political transition of the early 1990s, with reforms to maintain universal access and to address complex non-communicable diseases, are also instructive. At the same time, middle-income countries in other parts of the world provide a rich laboratory from which CEE/FSU countries can learn, with many examples of innovation from countries such as Brazil, Thailand and Vietnam.

There are signs of a shifting approach to health systems strengthening, with many South-South partnerships emerging, such as those linking Brazil, India, China and South Africa through the BRICS network. Unfortunately, Russia, the fifth member of this grouping, has failed to engage substantively in its health agenda so far.

What needs to change for CEE/FSU countries to become a bigger part of the health systems dialogue? One obvious problem is the way in which the term "global health" is interpreted. For many universities and funders, it refers only to health in low-income countries. Indeed, the Global Health Program of the Bill and Melinda Gates Foundation states its aim as to "harness advances in science and technology to save lives in poor countries" (3). In the same vein, a recent Lancet commentary (4) on global engagement for health after 2015 focused on sub-Saharan Africa. It is essential to seize every opportunity to reiterate that the word "global" means just that, encompassing the whole world, regardless of the level of development. It is now recognized that social inequities cause disproportionately poor health outcomes for disadvantaged people in all countries (5).

Another problem is weak health research capacity in CEE/FSU. Research capacity will not increase unless this issue is prioritized by governments in the region and by international funders. Attention should be given to improving training opportunities, funding relevant research and cultivating adequately remunerated career pathways that will attract and retain highly qualified researchers. Inspirational individuals from the CEE/FSU countries should be provided with a platform in global health policy debates. This will facilitate the development of evidence-based policies while also providing a basis for attracting additional European and international research funding. However, this can only happen if the global research community, including researchers in CEE/ FSU, advocate effectively for increased investment.

We believe that a global research organisation must reach out to include researchers wherever they live throughout the world. Health Systems Global will be in a much better position to influence the direction of research and of the post-2015 development 
agenda (6) if it engages experts from all forms of health systems - including those in CEE/FSU countries, which have valuable lessons to offer to the rest of the world. Health Systems Global has been launched at an exciting time. By encouraging a collaborative approach to building the evidence base, mentoring junior colleagues and facilitating the translation of research into action, this much-needed organisation can help lead the charge for truly universal health coverage and with it better health for all.

\section{Conflict of interest}

Dina Balabanova is a board member of Health Systems Global and Jeffrey Lazarus heads the secretariat in Copenhagen.

\section{REFERENCES}

1. Kraushaar D, Kieny MP, Lazarus JV, Bermejo R 3rd, Abimbola S, Prashanth N, et al. Health Systems Global, the new international society for health systems research. Health Policy Plan. 2012 Oct;27(7):535-40.

2. McKee M, Stuckler D, Basu S. Where there is no health research: what can be done to fill the global gaps in health research? PLoS Med. 2012;9(4):e1001209.
3. Bill and Melinda Gates Foundation. Programs \& partnerships. Global health program [Internet]. Bill and Melinda Gates Foundation; 2012 [cited 2012 Nov 27]. Available: http://www.gatesfoundation.org/global-health/ Pages/overview.aspx.

4. Carlsson G, Nordström A. Global engagement for health could achieve better results now and after 2015. Lancet. 2012 Nov 3;380(9853):1533-4.

5. World Health Organization; Commission on Social Determinants of Health. Closing the gap in a generation: health equity through action on the social determinants of health [Internet]. Geneva: World Health Organization; 2008 [cited 2012 Nov 27]. http://apps.who.int/iris/bitstre am/10665/43943/1/9789241563703 eng.pdf.

6. Beijing Statement from the Second Global Symposium on Health Systems Research [Internet]. Beijing, China; 2012 [cited 2012 Nov 27]. Available from: http://www.hsr-symposium.org/images/stories/downloads/ beijing\%20_statement.pdf.

Corresponding author:

Jeffrey V. Lazarus, Copenhagen University, Panum Institute,

Byg 21.1, Blegdamsvej 3B, Copenhagen N, Denmark. E-mail:

jla@cphiv.dk

Follow us on Twitter: @H_S_Global - @JVLazarus -

@martinmckee-@DinaBalabanova 